\title{
Understanding the Misbehavior of At-Risk Students: Contributing Factors
}

\begin{abstract}
A study was conducted on 113 at risk students in 25 secondary schools situated in five zones in Malaysia. The purpose of the study was to identify the psychological factors which contribute to their misbehavior and their low achievement in school. In-depth interviews were conducted and data were transcribed verbatim. The data were content analyzed to extract the factors contributing to at-risk students' deviant behavior. Among the factors identified were personal factors, family problems and peer influence. Personal factors include low selfesteem, troubled personality and indiscipline. Family problems include poor parental monitoring, poor interaction with children, low income and marital problems. Peer influence includes peer pressure, peer modeling and peer support. Implications of the findings are discussed for the future well-being of the children.
\end{abstract}

Keyword: At-Risk Students 